\title{
Critical care: American Board of Thoracic Surgery update
}

\author{
William A. Baumgartner, MD, ${ }^{\mathrm{a}}$ John H. Calhoon, MD, ${ }^{\mathrm{b}}$ Richard J. Shemin, MD, ${ }^{\mathrm{c}}$ and Mark S. Allen, $\mathrm{MD}^{\mathrm{d}}$
}

Dr Nevin Katz ${ }^{1}$ states in his editorial titled "It is time for certification in cardiothoracic critical care" that the American Board of Thoracic Surgery (ABTS) deliberated on this very point beginning in summer 2008. After serious consideration, it was determined that, for a variety of reasons, it was too early to consider separate ABTS certification in the area of critical care. At this stage, in 2013, the ABTS continues to hold that opinion, which is explained in the following few paragraphs.

After that 2008 meeting, Dr Valerie W. Rusch, Chair, ABTS Board of Directors, formed a Critical Care Committee within the ABTS structure. Working with a variety of directors, including Dr J. Wayne Meredith, American Board of Surgery (ABS) Representative to the ABTS, Dr Rusch and her committee collaborated with the ABS to create a Critical Care Fellowship with a "cardiothoracic emphasis" within the current ABS certificate fellowship program for critical care.

The requirements for this critical care fellowship are similar to the standard ABS critical care fellowship. Residents in a fellowship, 3 years after initiation of an Accreditation Council for Graduate Medical Education residency program, or certified ABTS Diplomates can participate. It requires 12 continuous months, with 4 to 6 months being dedicated to cardiothoracic surgery critical care. Successful completion of the fellowship results in the award of an ABS certificate. In the case of a resident, the certificate is granted after the completion of the primary certification process.

This ABS certificate in critical care for cardiothoracic surgery was approved by the Surgery Residency Review Committee and was made available to programs in 2011. To date, we are aware of only one institution, University of Washington, Seattle, Washington, that has developed such a program. It is of note that no resident has yet completed this specialized cardiothoracic critical care program.

With the recent interest in critical care, the ABTS wanted to reemphasize that critical care has always been a core component of ABTS certification. It, along with adult cardiac, general thoracic, and congenital, make up the

From the Johns Hopkins Hospital, ${ }^{\text {a }}$ Baltimore, Md; the University of Texas Health Science Center, ${ }^{b}$ San Antonio, Tex; the University of California-Los Angeles, ${ }^{c}$ Los Angeles, Calif; and the Mayo Clinic, ${ }^{\mathrm{d}}$ Rochester, Minn.

Disclosures: Authors have nothing to disclose with regard to commercial support.

Received for publication Feb 22, 2013; accepted for publication Feb 27, 2013; available ahead of print March 25, 2013.

Address for reprints: William A. Baumgartner, MD, Johns Hopkins Medicine, Miller Research Building, Suite 115, 733 N Broadway, Baltimore, MD 21205 (E-mail: wbaumgar@csurg.jhmi.jhu.edu).

J Thorac Cardiovasc Surg 2013;145:1448-9

0022-5223/\$36.00

Copyright (C) 2013 by The American Association for Thoracic Surgery

http://dx.doi.org/10.1016/j.jtcvs.2013.02.059 four key elements of certification through the ABTS. It makes up a significant part of the educational curriculum (see ABTS Web site), results in questions for the written, oral, and maintenance of certification examinations, and is defined in all ABTS materials, including the Web site. The following is a statement in the ABTS Booklet of Information that appears on our Web site, "The American Board of Thoracic Surgery considers it inappropriate to exclude its Diplomates from credentialing for care of thoracic surgical patients in a critical care setting based on the Diplomate's training or board certification. Our Diplomates have been trained in critical care management of thoracic surgical patients and they have successfully completed both written and oral examinations, which cover the critical care aspects of thoracic surgical patient management." When requested, the executive director of the ABTS will write a letter on behalf of the Diplomate to the specific credentials committee if the Diplomate is not able to care for his or her patients in the intensive care unit. With critical care being a core component of ABTS certification, a compelling argument can be made in support of the requesting Diplomate.

The ABTS applauds Dr Katz and his colleagues for their enthusiastic support of critical care conferences, both standalone and in association with the annual meetings of the Society of Thoracic Surgeons and The American Association for Thoracic Surgery. These conferences provide necessary ongoing education for Board-certified thoracic surgeons in the critical care of patients.

Although it is often stated that thoracic surgeons have difficulty caring for a patient in the intensive care unit, the number of letters of request to the ABTS is in the range of 2 to 3 per year. It will continue to be our policy to defend rigorously our Diplomates who are denied the opportunity to care for their patients in an intensive care unit setting.

It is also important to explain some of the procedural barriers to an independent certificate through the ABTS. On the Accreditation Council for Graduate Medical Education Web site, in both the Common Program Requirements as well as Frequently Asked Questions, it states: "the program director is expected to be an expert in the specific field of the program, current Board Certification is the minimum benchmark of expertise." Part of the requirement for a successful approval of a separate ABTS certification in critical care would be a core number of ABTS-certified Diplomates who are also certified in critical care. There are less than 30 ABTS critical care-certified thoracic surgeons in academic training institutions. Because there is considerable overlap in the care of critically ill patients, the ABS fellowship would meet the educational requirements of cardiothoracic surgery in its current specialized fellowship makeup. In 
addition, there is no doubt that, during the long formal American Board of Medical Specialty process, there would be considerable opposition from the other boards, including Medicine, Anesthesiology, and Surgery. As Dr Katz points out in his editorial, there is always the possible disenfranchisement of other cardiac surgeons, the majority of which would not have an ABTS certificate in critical care.

Considering our current arrangement with the ABS and the ABTS's commitment to advocate on the part of the Diplomate's request, the ABTS will continue its current policy with periodic reevaluation, recognizing that, sometime in the future, there should be a core group of ABTScertified cardiothoracic surgeons who are also certified in critical care, which would allow the ABTS to take the first step toward an independent ABTS critical care certificate.

\section{Reference}

1. Katz NM. It is time for certification in cardiothoracic critical care. $J$ Thorac Cardiovasc Surg. 2013;145:1446-7. 